\title{
Inserción Social de los Refugiados Colombianos en Manaos, Brasil ${ }^{*}$
}

Social Insertion of Colombian Refugees in Manaus, Brazil

Recepción: 23 Abril 2016 | Aceptación: 21 Febrero 2018

\author{
Julio César Pinto de Souza \\ Universidade Federal do Amazonas, Brasil \\ ORCID: http://orcid.org/0000-0003-3622-1393 \\ Marcelo Gustavo Aguilar Calegare \\ Universidade Federal do Amazonas, Brasil \\ ORCID: http://orcid.org/0000-0001-6814-5300
}

\footnotetext{
a Autor de correspondencia. Correo electrónico: cmte01@yahoo.com.br
}

Para citar este artículo: Pinto de Souza, J. C. \& Aguilar Calegare, M. G. (2018). Inserción Social de los Refugiados Colombianos en Manaos, Brasil. Universitas Psychologica, 17(4), 1-10. https://doi.org/ 10.11144/Javeriana.upsy17-4.isrc

\section{RESUMEN}

Este artículo describe el proceso de inserción social de las familias de refugiados colombianos en Manaos (Amazonas, Brasil), discutiendo cuestiones de identidad cultural y de conflictos con la sociedad local. La investigación cualitativa de carácter exploratorio-descriptivo se realizó en dos etapas: a) investigación documental del banco de datos de la pastoral del migrante, que identifica el perfil de los refugiados (género, edad, escolaridad y ciudad de origen), especialmente colombianos, que estuvieron en Manaos entre enero del 2013 y diciembre del 2014; b) entrevista semiestructurada con las familias establecidas en la ciudad. Analizamos los datos por estadística descriptiva y análisis de contenido, respectivamente. De las 159 personas que solicitaron refugio, 90 eran colombianos que huyeron de su país por causa de la inseguridad y la violencia de las fuerzas paramilitares. La inserción social de las únicas 4 familias que se asentaron en la ciudad fue facilitada por la acogida de la pastoral, pero el idioma, los conflictos familiares, de trabajo y vivienda hicieron más difícil la estadía en la nueva ciudad. Las costumbres y tradiciones fueron importantes para mantener la identidad colombiana, aunque el miedo a ser identificado por otros compatriotas hizo que no se incorporaran al grupo. Hay prejuicio y discriminación de los grupos locales sobre los refugiados colombianos. Concluimos que, a pesar de haber una ley para refugiados en Brasil, no hay ninguna estrategia que facilite la inserción social en la sociedad local.

Palabras clave

refugiados; colombianos; inserción social; Manaos; identidad.

\section{ABSTRACT}

This article describes the social insertion process of Colombian refugees' families in Manaus (Amazonas, Brazil), discussing about cultural identity issues and conflicts with the local society. The qualitative research with an exploratory and descriptive character occurred in two phases: a) documentary research in the database of the migrant pastoral to identify the refugees profile who passed through Manaus between January, 2013 and December/2014, specially the Colombians (gender, age, scholar degree, precedence); b) semi-structured interviews with the families settled in Manaus. We analyzed the data through descriptive statistics and content analysis, respectively. Among the 159 refuge requesters, 90 were 
Colombian, which fled their country due to insecurity and violence of the paramilitary forces. The social inclusion of the only 4 families that remained in Manaus was facilitated for reception of the pastoral, but the language, familial problems, work and housing made it difficult. The customs and traditions act to maintain the Colombian identity, but the fear of being identified by other Colombians make them not insert to this group. There is prejudice and discrimination of local groups about the Colombian refugees. We conclude that despite the existence of a refugee law in Brazil, there is no strategy that facilitates the social insertion in the local society.

Keywords

refugees; Colombian; social insertion; Manaus; identity.

El fenómeno social del refugio ha sido acompañado por la Organización de las Naciones Unidas (ONU), y por investigadores de movimientos migratorios desde la Segunda Guerra Mundial, después de la masiva evasión de personas de sus respectivas tierras natales hacia otros países. En 1951, la ONU estableció una convención que dio origen al estatuto de los refugiados. Para su cumplimiento, se estableció el Alto Comisionado de las Naciones Unidas para los Refugiados (ACNUR), cuya labor es asegurar los derechos y el bienestar de los refugiados, y perseverar en garantizar a cualquier persona el derecho de encontrar y gozar de un refugio seguro en otro país (Barreto, 2010). De acuerdo al estatuto, un refugiado es toda persona que está fuera de su país natal por temores fundados de persecución relacionados con su raza, religión, nacionalidad, grupo social u opinión política (ACNUR, 2010). Actualmente, la definición de refugiados fue ampliada, y se incluyeron, además, las personas obligadas a dejar su país debido a conflictos armados, violencia generalizada y violación masiva de los derechos humanos.

El refugio ha ganado reconocimiento en los últimos años por los grandes movimientos de masas poblacionales, especialmente en Europa, África y Medio Oriente. En 2013, existían 16.7 millones de refugiados en el mundo y, en 2015 se sobrepasaron los 20 millones, alcanzando una marca histórica (ACNUR, 2014). En América del Sur, Brasil es el país más buscado en función de la política de acogida a refugiados, con una legislación interna bien estructurada: la Ley $n . \stackrel{o}{ }$
9474 de 1997, conocida como la ley del refugiado (Soares, 2012). Hasta la mitad del 2015, fueron reconocidas 7762 solicitudes de refugio por el gobierno brasileño, en donde los colombianos fueron el segundo grupo más grande, superado solo por los sirios (ACNUR, 2015).

Parte de esos colombianos entra por la región norte de Brasil, por la ciudad de Tabatinga (estado de Amazonas), área conocida como triple frontera (Brasil, Colombia y Perú). Una pequeña parte entra por la ciudad de Pacaraima (estado de Roraima), en la frontera con Venezuela. Después de estar en Brasil, es común que se desplacen hacia Manaos, capital del estado de Amazonas, donde son recibidos por la Pastoral del Migrante, perteneciente a la iglesia católica, que actualmente es la entidad socia del ACNUR para la acogida de refugiados. Hasta 2014, la mayoría de las familias de refugiados que se presentaron en Manaos era de origen colombiano, víctimas de los conflictos armados, violencia e inseguridad vividas en su país de origen.

La acogida ofrecida ameniza un poco la incomodidad de esas personas, que abandonan sus hogares, familias y lugar de pertenencia de forma involuntaria y abrupta, para recomenzar sus vidas en otro país. Muchos refugiados llegan con serias restricciones financieras, y deben enfrentarse a un idioma diferente, la inexistencia de un hogar y la dificultad para conseguir un trabajo. Todo eso se potencializa por una cuestión de conflictos grupales, resultantes de la atribución de estereotipo negativo hacia los refugiados, y prejuicios y discriminación por parte de algunos grupos locales, debido a que la llegada de grupos extranjeros no siempre es bien vista por los pobladores locales (Elias \& Scotson, 2002; Goffman, 1988). Según Oliveira (2010), hay dificultad de inserción de las familias colombianas en Manaos por ser vistas como aquellas que traen una cultura e idioma diferentes, y llegan para robar los empleos de los manauaras.

Ante ese escenario, en este artículo tenemos como objetivo describir el proceso de inserción social de las familias de refugiados colombianos en Manaos (Amazonas). Para eso, inicialmente 
identificamos el origen de los solicitantes de refugio, entre 2013 y 2014, que pasaron por la Pastoral del Migrante en Manaos, pero enfocándonos solo en la identificación del perfil de los refugiados colombianos. De aquellas familias que permanecieron en la ciudad, describimos el proceso de inserción social, discutiendo cuestiones de identidad cultural y de conflictos con la sociedad local.

\section{Método}

Esta investigación es de abordaje cualitativo y de carácter exploratorio-descriptivo (Markoni \& Lakatos, 2008), y siguió dos etapas: una cuantitativa y otra cualitativa.

\section{Etapa cuantitativa}

En la primera etapa realizamos la investigación documental del banco de datos de la Pastoral del Migrante, en donde se obtuvieron datos referentes a los refugiados colombianos. El primer paso fue buscar los archivos existentes sobre solicitudes de refugio entre enero de 2013 y diciembre de 2014. Todos los archivos se encontraban registrados en una computadora, en tablas del programa Excel, y administrados por la asistente social de la Pastoral del Migrante. El número encontrado fue de 159 solicitudes de refugio durante ese periodo. En seguida, se enfatizó solo en los refugiados colombianos, y se obtuvo una cantidad de 90 que solicitaron refugio. Luego se buscaron los datos disponibles en las tablas, donde se encontró información de género, edad, escolaridad y ciudad de origen. Esos datos fueron tabulados y analizados según estadística descriptiva.

\section{Etapa cualitativa}

En la segunda etapa, estudiamos solo a las familias de colombianos que solicitaron refugio durante el período estipulado, en donde se llegó a 9 familias. Sin embargo, solo 4 continuaban residiendo en Manaos durante la realización de la investigación. Nosotros las entrevistamos en sus residencias o en un lugar reservado estipulado por ellos, entre diciembre de 2014 y febrero de 2015, a través de entrevistas semiestructuradas, que fueron grabadas y examinadas por análisis de contenido (Bardin, 2011).

Por tratarse de una investigación con seres humanos, seguimos todos los aspectos éticos pertinentes, incluyendo la aprobación del Comité de Ética en Investigación (n⿳0 842.570). En ese sentido, en este artículo utilizamos pseudónimos para todas las familias y personas citadas por los refugiados durante las entrevistas.

\section{Resultados y discusión}

\section{Perfil de los refugiados en Manaos}

A partir de la investigación del banco de datos de la Pastoral del Migrante, encontramos registros de 159 solicitantes de refugio, donde un $39.6 \%$ de las solicitudes ocurrió en 2013, y un $60.4 \%$ en 2014. De ese total, $57 \%$ son de Colombia (46 solicitudes en 2013 y 44 en 2014), 29 \% de otros países de América Latina (Cuba, Ecuador, Perú, República Dominicana y Venezuela), $8 \%$ de África (Ghana, Nigeria, República Democrática del Congo y Somalia) y 6 \% de Asia (Afganistán, Bangladesh y Siria).

De los colombianos que solicitaron refugio, 81 $\%$ son hombres y $19 \%$ son mujeres. De estos, el 79 \% tenía entre 41 y 50 años, un $1 \%$ más de 60 años, y el restante $20 \%$ menos de 18 años. En cuanto a la escolaridad, $54 \%$ tenía enseñanza primaria, $45 \%$ enseñanza secundaria y solo $1 \%$ enseñanza superior. Hasta diciembre del 2014, permanecieron en Manaos solo el $26 \%$ (23) de esos solicitantes, de los cuales 6 eran personas que vinieron solas, y 4 con grupos familiares: familia Bautista (pareja y 3 hijos), familia Carbonell (pareja y 3 hijos), familia Muñoz (mujer y 2 hijas), familia Soarez (pareja y 2 hijos). El motivo unánime para la solicitación de refugio de esas familias fue la violencia infligida por los grupos paramilitares vinculados al narcotráfico en la región donde vivían, siendo que la familia Muñoz 
ya había sido desplazada antes de migrar a Brasil. El siguiente relato ejemplifica ese motivo:

"Digamos, yo no sé los problemas de mi... de la familia de mi esposo. Porque... Allí los mataron a todos ellos. Solo lo sé porque mi esposo me decía que lo amenazaron, por los problemas que ellos tenían" (familia Soarez).

En América Latina, la mayoría de refugiados proviene de Colombia. El motivo principal es el conflicto armado infligido por las fuerzas paramilitares y por las fuerzas armadas revolucionarias de Colombia (FARC), que han producido tanto desplazados dentro del propio país como refugiados en otros países (Silva, 2010). Oliveira (2008) menciona también otros motivos como la pobreza, la opresión política, la ausencia de redes de seguridad, la aceleración de la urbanización y la falta de participación en procesos políticos. De acuerdo con la Human Right Watch (2010), los grupos paramilitares son extremamente brutales, e impactan en la situación humanitaria y de los derechos humanos de la población colombiana, que sufre con abusos graves y generalizados como masacres, ejecuciones, violaciones, amenazas y extorsión.

Silva (2010) complementó con la idea de que el conflicto armado en Colombia produjo un desplazamiento de masas poblacionales en las fronteras del país. A pesar de que muchos colombianos prefieren Ecuador y Venezuela por la similitud del idioma, muchos migran a Brasil por la proximidad geográfica, por lo que se estima que existen entre 15 y 20 mil colombianos en la Amazonía brasileña que necesitan protección internacional (Araújo, 2009). Eso revela que el refugio no es una opción en busca de mejores condiciones de trabajo y vivienda, sino una imposición acarreada por el miedo y por la violencia diseminados, especialmente por las fuerzas paramilitares.

Corroborando con los datos recolectados, Silva (2010) encontró que el grupo etario de los colombianos que piden refugio en Manaos varía de 35 a 50 años y, en general, migran con toda la familia. Con el objetivo de encontrar, con mayor facilidad, mejores empleos y más seguridad, muchos acaban optando por desplazarse a otros estados como São Paulo, Minas Gerais y Río de Janeiro.

\section{La inserción social en Manaos}

Al llegar a Manaos, tres familias tuvieron apoyo de familiares que ya se encontraban residiendo en la ciudad, lo que facilitó la acogida inicial y la inserción social de forma sensible, pues ofrece en las primeras semanas toda la estructura necesaria para su instalación en la ciudad y la seguridad de un ente querido al lado. La familia que llegó sin tener ningún pariente o conocido recibió el apoyo de la Pastoral del Migrante, que ofreció vivienda, alimentación y ayudó en la obtención de documentos para trabajar. Actualmente, todas las familias viven en casas alquiladas, en barrios de clase baja de Manaos, y afirman que les gusta el lugar en el que viven, excepto la familia Bautista que afirma que no le gusta la casa donde reside, pues la considera muy pequeña.

Las familias presentan cierto distanciamiento en las relaciones de amistad con los vecinos y la comunidad local, excepto por la familia Soarez, que posee una relación de ayuda mutua con la vecindad. Sin embargo, una familia comentó la buena relación que tienen sus hijos con otros niños de la comunidad. Esa relación fomenta el sentimiento de pertenencia, y favorece la inserción social de toda la familia, que pasa a construir una identidad social positiva con la comunidad (Deschamps \& Moliner, 2014). Todos los niños de las familias entrevistadas frecuentan la escuela, lo que es controlado por la asistente social de la pastoral.

Con respecto a la participación en actividades sociales, se encontró que la familia Soarez socializa con otras familias, mientras que las familias Muñoz y Bautista poseen una socialización limitada, y la familia Carbonell no socializa. La participación en las actividades sociales de la comunidad prácticamente se limita a asistir a la iglesia, o a conversaciones rápidas en la puerta de casa. Se muestra con eso que la relación con los vecinos está marcada por la distinción entre grupos, característica que 
define el comportamiento intergrupal (Alfinito \& Corradi, 2011).

En relación con actividades de esparcimiento, todos dijeron que salen a pasear a lugares públicos. La familia Muñoz, además, citó almuerzos los fines de semana con la familia y conocidos. Para Woodward (2014), el acto de comer es más que la necesidad básica de alimentarse, pues la culinaria es un lenguaje a través del cual hablamos de nosotros mismos y de nuestro lugar en el mundo.

De la inserción profesional, dos familias consiguieron empleos fijos, mientras que las otras dos trabajan de forma esporádica; todos en actividades similares o iguales a aquellas ejercidas en Colombia: auxiliares de hotelería, empleada doméstica y auxiliares de construcción civil. Eso desmitifica, por lo menos en el grupo investigado, que los refugiados ocupen subempleos por una restricción del mercado de trabajo (Silva, 2010), pues la dificultad está en la falta de calificación profesional, que hace que se mantengan en la misma profesión que tenían anteriormente. Araújo (2009) comentó que uno de los grandes desafíos de los refugiados en Brasil es insertarse en el mercado de trabajo y conseguir una condición social digna. Al no haber ninguna política pública de inserción profesional para los refugiados, ellos se ven a merced de los puestos ofrecidos por el mercado de trabajo. En la capital de Amazonas, es común que esos servicios ejecutados por ellos sean esporádicos.

$\mathrm{Al}$ investigar qué facilitó el proceso de inserción social, las familias de refugiados colombianos que residen en Manaos relataron tres categorías de facilitadores: el estudio de los hijos, la acogida inicial recibida y las posibilidades de remuneración. Conforme a lo que se verifica en los trechos destacados:

"Mis hijos ahora están estudiando y yo creo que es más fácil, como familia, vivir aquí en Manaos" (familia Soarez).

"Entonces yo pienso que la doctora Ana Cristina, en la casa abrigo, la doctora... Me trataron muy bien, me ayudaron con los documentos, nos dieron alimentos. Nos trataron muy bien" (familia Muñoz).
"Mi vida es más fácil aquí en Manaos por lo que es... Aquí uno sale a trabajar, sale sin nada, uno... Ya a la tarde uno ya llega con platita. ¿Sí, me entiendes? Y eso allá en Colombia no lo hay" (familia Carbonell).

En cuanto a las dificultades vividas por las familias, además de la distancia y de la nostalgia de su casa natal, de los familiares y del país, se elaboraron cuatro categorías para las respuestas dadas: idioma, problemas conyugales, trabajo y vivienda. Algunos ejemplos de esas dificultades pueden observarse en las declaraciones seleccionadas:

"El idioma. La gente no me entendía, todo era con señal, todo" (familia Muñoz).

"Entonces... Otra cosa también que... Ahora a veces tenemos así, problemas con mi marido, esas cosas. A veces es... Muchas peleas con mi marido" (familia Soarez).

"Más difícil que no tengamos donde vivir, así, como una ayuda para poder vivir un poco mejor (...) Pues aquí la única dificultad es el trabajo" (familia Bautista).

Aun con la dificultad estructural y de personal existente en la Pastoral del Migrante, además de la falta de apoyo del gobierno brasileño, se verifica que uno de los factores que los refugiados consideran como positivo para el proceso de inserción social es la acogida ofrecida por esa institución. El apoyo recibido involucra recursos financieros en los primeros meses y auxilio para obtención de algunos documentos. Cuando hay niños y adolescentes en el grupo, los mismos son encaminados hacia escuelas próximas a la región donde reside el refugiado, con el fin de matricularlos. Con esas acciones de apoyo, los refugiados relatan sufrir menos con el cambio de país.

Con relación a las dificultades encontradas para la inserción social, los refugiados declaran que la distancia del país y de los familiares son aspectos negativos, así como la falta de una casa para vivir y los problemas intrafamiliares, ya que el refugiado no cuenta con la presencia de parientes cerca para recurrir ante conflictos familiares. Sin embargo, uno de los principales aspectos examinados es la diferencia del idioma, que dificulta la comunicación y propicia un 
aislamiento entre ellos y la población local. Al respecto del idioma, Coelho y Mesquita (2013) comentaron que este es la base en la que se apoya la vida social en los días actuales, visto que realiza la mediación de las relaciones sociales y permite la inscripción del individuo en este o en aquel grupo social. Más que eso, el idioma es el elemento central en el proceso de construcción de la identidad nacional, pues "por medio de actos de habla instituimos la identidad y la diferencia como tal" (Silva, 2014, p. 77). Para Hall (2011), el idioma es de extrema importancia para la inserción de los grupos que migran hacia un país de idioma diferente, pues esto es lo que diferencia los grupos y produce una identidad, por medio de la diferencia cultural y social del grupo.

Identidad colombiana y relación con otros colombianos

A pesar de la situación de refugio, al investigar al respecto del sentimiento de ser colombiano, todas las familias dijeron sentirse orgullosos de eso, afirmando que expresan su identidad colombiana principalmente por la preservación de la culinaria, la música y las fiestas:

"La comida y la fiesta. Hago solo las de mi tierra" (familia Soarez).

"La comida. Yo cocino para los colombianos" (familia Muñoz).

"La comida. Música también, escuchamos música" (familia Bautista).

"Ah, sí. Yo hago comida colombiana en casa" (familia Carbonell).

A pesar de estar en otro territorio, la identidad colombiana todavía existe activamente en los refugiados entrevistados. Esto sucede porque su construcción ocurre a través de la posición que se asume, y con la cual se identifica cada uno (Silva, 2014). Además de eso, Berlatto (2009) aclaró que la identidad se refiere al sentimiento de pertenencia a determinado grupo social y se expresa en un conjunto de vínculos con el sistema social, en el caso la propia nación, culinaria, música, entre otras. De ese modo, al mantener las costumbres de su país de origen, esas familias de refugiados colombianos están manteniendo su identidad nacional, que según Phinney (2004) se refiere al "sentimiento de pertenencia a un país o estado soberano" (p. 50). El autor además comenta que esta identidad puede transformarse de acuerdo con el sentimiento de lealtad que el refugiado tenga de su nuevo país, por el hecho de que la identidad no es estática, sino dinámica. Puede haber en el futuro una hibridación de la identidad colombiana con la identidad brasileña, en los términos de Hall (2011), lo que exigiría una investigación posterior para la verificación de esa transformación de la identidad.

Sentirse colombiano va más allá de mantener costumbres y tradiciones. Es también convivir con otros colombianos que comparten eso. De ese modo, investigamos cuál es la relación que las familias de refugiados poseen con otros colombianos. Las familias Bautista y Carbonell presentaron un distanciamiento con otros colombianos en Manaos, mientras que algunos miembros de la familia Soarez se relacionan, y otros no. Solamente la familia Muñoz relató una buena relación con otros colombianos. Veamos esas relaciones en las siguientes declaraciones:

"No tengo, así, mucho contacto" (familia Bautista).

"Cuando hay reunión, así, cuando los encuentro, (...) así, ya uno saluda, uno se va" (familia Carbonell).

"Tampoco nunca me trato con muchos colombianos, no. Solo saludo y ya. Mi esposo, sí, tiene muchas relaciones con muchos colombianos" (familia Soarez).

"Ay, yo encuentro a muchos colombianos, muy bien, muy bien porque somos como... Por el hecho de ser colombianos, ya somos familia aquí. Es bueno" (familia Muñoz).

Se entiende que la migración y el refugio están revestidos de inseguridad de lo desconocido, pues migrar es "salir de su lugar, involucrando procesos de desterritorialización y reterritorialización" (Marandola Jr. \& Gallo, 2010). Como complemento a esa idea, Moreira (2005) comentó sobre la existencia de algunos casos de refugiados colombianos que viven en constante estado de tensión, temiendo por su seguridad en el territorio brasileño, debido a la 
proximidad con Colombia. Por eso, entendemos que la relación entre los propios refugiados colombianos sea distante. El miedo de ser identificado se vuelve plausible debido a los muchos colombianos en Manaos. En cuanto a ese recelo, Souza, Lima y Oliveira (2012) señalaron la existencia de casos de refugiados colombianos que tienen miedo de revivir los horrores y las amenazas que sufrieron cuando vivían en su país natal, por lo que desarrollan una aversión hacia sus compatriotas. Según nuestro punto de vista, ese es también uno de los motivos que hace que muchos colombianos se desplacen a otras regiones del país.

\section{La identificación como refugiado}

Se buscó entender cuál es la percepción de las familias en cuanto a la identificación como refugiado. Tal entendimiento fue diverso, conforme a lo que se verifica en las siguientes declaraciones:

Es como decir que... Como se dice en Colombia, como decir arrimada. No tengo casa, entonces... Vivo como cucaracha, tú las barres y vuelven a entrar. Eso no me gusta, cómo dicen "refugiada" (familia Soarez).

"Por decir algo, el estado de Brasil me da como un asilo, lo llamamos en Colombia, como un asilo" (familia Muñoz).

"Yo pensaba que era... Era un poco más fácil llegar a otro país siendo refugiado" (familia Bautista).

"Refugiada sería como si viniera como a escondidas" (familia Carbonell).

Todos los refugiados se identifican como tal, sin embargo presentan percepciones diferentes. Lo que llama la atención es que tienen un sentimiento de quien huyó de su país y que ahora no tiene un lugar donde quedarse, comparándose a las cucarachas. De acuerdo con Silva (2010), esta percepción también es compartida por un solicitante de refugio, que afirma que los refugiados "son vistos como moradores de calle” (p. 209). Ese entendimiento no es del todo equivocado; según el autor, aquellos refugiados que no consiguen ayuda de redes sociales de apoyo, solo tienen la opción de deambular y vivir por las calles de la ciudad.

Más que solamente la autoidentificación en cuanto refugiado, esa identidad está constituida por la relación que los refugiados - como grupo social- establecen con la sociedad que los recibe (Hall, 2011; Silva, 2010; Silva, 2014). Y dependiendo de cómo son las interacciones intergrupales, puede haber interferencia en el sentimiento de pertenencia de los colombianos a la sociedad anfitriona. De esa forma, investigamos qué percepción tienen las familias de refugiados sobre la que los manauaras tienen a su respecto. Las familias Soarez y Bautista perciben a los manauaras como prejuiciosos con relación a los refugiados colombianos, mientras que las familias Muñoz y Carbonell no declaran ser blanco de prejuicio explícito, a pesar de ser blanco de algunas bromas. Los siguientes trechos muestran este punto:

"Entonces... El brasileño pasa como bromeando. Y dice: 'hola, colombiano... ¿Cuánto polvo blanco trajiste? ¿Traje?'. Entonces eso es otra cosa que no me gusta por ser colombiano. Porque ellos repiten mucho que los colombianos son los que traen mucha droga. 'Traje polvo blanco, o traje marihuana', esas cosas" (familia Soarez).

"No, siempre hay uno u otro que no saben, no les gusta" (familia Bautista).

Aunque de forma jocosa, las familias entrevistadas relatan que son blanco de prejuicio y discriminación al declararse refugiados. Para Pérez-Nebra y Jesus (2011), la discriminación se genera cuando el prejuicio se transforma en acción, que es una actitud relacionada con creencias negativas sobre el objeto, que puede tener su génesis en el contexto social y cultural del individuo. O sea, la aprensión está basada en la percepción de homogeneidad en grupos, y puede transformarse en discriminación, que genera segregación de un grupo por parte de otro.

Silva (2014) argumentó que la identidad y la diferencia están intrínsecamente relacionadas, $\mathrm{y}$ al ser puestas en un sistema clasificatorio y jerarquizado de quién vale más —o de quién tiene razón o está equivocado-, eso sienta precedentes de prejuicio y discriminación del 
grupo que se considera como elemento central, con relación a aquel considerado periférico. El autor da un ejemplo de la clasificación simbólica de un forastero, que por no ser habitante local se tiene como que desentona el orden social $y$, por lo tanto, es una persona peligrosa que debe ser separada y marginalizada. En esa misma línea, Oliveira (2008) resaltó que los inmigrantes son doblemente indeseados: llegan trayendo otra cultura y les roban los empleos a los habitantes locales.

Una de las cuestiones expuestas por una de las familias a la que no le gustaba decir que era colombiana por asociar al colombiano con el tráfico de drogas, se muestra muy presente en la sociedad manauara. Según Silva (2010), "para el sentido común, 'colombiano' es sinónimo de 'traficante' hasta que se pruebe lo contrario" (p. 214). A pesar de tener una intención solamente de broma o burla, existe una cuestión más importante en esa designación. Al preguntársele a un brasileño si todos los colombianos son traficantes, probablemente dirá que no, sin embargo es por medio de esa característica que se clasifica un colombiano, destacando tal prejuicio. Cuando se dice algo respecto a características de un grupo cultural, se piensa que estamos describiendo una situación existente, pero lo que se dice constituye una red de actos lingüísticos que coopera en la definición o refuerzo de la identidad que supuestamente solo se está describiendo (Silva, 2014).

Se entiende con eso que al preguntarle a un refugiado colombiano si ya traficó drogas o si ya mató a alguien solamente por el hecho de ser refugiado, ya estamos diferenciándolo de nuestro grupo, poniéndolo en una posición de inferioridad. Tal entendimiento es percibido por Goffman (1988) no solo como un atributo personal, sino también como una forma de designación social. Esa estigmatización impone a los refugiados una posición de inferioridad y refleja el prejuicio que sufren por la sociedad local.

Siguiendo esa misma comprensión, Elias y Scotson (2002) comentaron que la estigmatización de los outsiders - los forasteros, migrantes, refugiados, etc.- es como un proceso de reificación, y que retira del grupo estigmatizador cualquier responsabilidad. En otras palabras, para los establecidos la sociedad local-, los outsiders poseen verdadera y concretamente atributos negativos, sin considerar que eso es una operación simbólica. De ese modo, aquellos que llaman a los colombianos traficantes y matadores se eximen de la responsabilidad de la estigmatización despreciativa, por considerar que esas personas de hecho practican tales actos. En suma, la estigmatización, el prejuicio y la discriminación son fenómenos que provienen de un proceso social que produce las identidades y las diferencias de los establecidos (los brasileños, la nación anfitriona) y los outsiders (los refugiados, los colombianos).

\section{Conclusiones}

La violencia de los grupos paramilitares en Colombia ha generado el escape de personas hacia fuera de sus ciudades natales, volviéndolas desplazadas o refugiadas. Aquellas que vienen a Brasil, país con tradición en la acogida a migrantes y que dispone de una ley para los refugiados, se enfrentan, no obstante, a una serie de dificultades: inserción profesional, idioma, distancia de los familiares, falta de un hogar, entre otras cosas. Nuestro estudio reveló que la inserción social de las familias de refugiados colombianos viene ocurriendo con cierta limitación, lo que puede ser atribuido, en parte, a la tímida participación en ese proceso por parte de las esferas del gobierno brasileño. La única acción gubernamental es aceptar la solicitud de refugio, lo que solamente ocurre después de algunos meses. Como vimos, es la labor de una institución de la iglesia católica la pastoral del migrante- hacer el trabajo de acogida inicial a los refugiados.

Según nuestro entendimiento, hay una falta de una estrategia efectiva de acogida, que se expresa en la carencia de políticas sociales que propicien condiciones para que una familia llegue a Brasil y se reestructure. Eso contribuye a que los refugiados sean vistos como aquellos 
que vienen a robar empleos, incluso sin tener calificación profesional suficiente para ocupar buenos puestos de trabajo. Y también da margen a la estigmatización, prejuicio y discriminación de la sociedad local con relación a los refugiados colombianos, que poseen un sentimiento ambivalente de ser colombianos: sienten orgullo de ser oriundos de su país, pero sienten miedo de ser identificados ante sus semejantes.

\section{Agradecimientos}

Agradecemos el apoyo del programa "Vamos Publicar" para la traducción de este artículo, que es fruto de la disertación de maestría del primer autor, defendida en el programa de Postgrado en Psicología de la Universidad Federal del Amazonas.

\section{Referencias}

Alfinito, S., \& Corradi, A. A. (2011). Contato intergrupal: conflito realístico privação relativa e equidade. En C. V. Torres, \& E. R. Neiva (Orgs.), Psicologia Social: principais temas e vertentes (pp. 262-286). Porto Alegre, Brasil: Artmed.

Alto Comisionado de las Naciones Unidas para los Refugiados. (2010). Lei $n^{\circ}$ 9474/97 e coletânea de instrumentos de proteção internacional dos refugiados (3a ed.). Brasilia, Brasil: Servidéias.

Alto Comisionado de las Naciones Unidas para los Refugiados. (2014). Tendencias Globales 2013: el coste humano de la guerra. Recuperado de http://www.acnur.es/PDF/a cnur_tendenciasglobales2013_web_20140 619124652.pdf

Alto Comisionado de las Naciones Unidas para los Refugiados. (2015). Mid-year trend 2015. Ginebra, Suiza: Autor. Recuperado de http ://www.unhcr.org/56701b969.html

Araújo, L. A. (2009). O Brasil e os problemas contemporâneos dos refugiados (Trabajo de grado sin publicar). Universidad de Brasilia, Brasil.
Bardin, L. (2011). Análise de conteúdo. Lisboa, Portugal: Edições 70.

Barreto, L. P. F. (2010). Refúgio no Brasil: a proteção brasileira aos refugiados e seu impacto nas Américas. Brasilia, Brasil: Ministério da Justiça.

Berlatto, O. (2009). A construção da identidade social. Revista do curso de direito da FSG, 3(5), 141-151.

Coelho, L. P., \& Mesquita, D. P. C. (2013). Língua, cultura e identidade: conceitos intrínsecos e interdependentes. Entreletras, 4(1), 24-34.

Deschamps, J. C., \& Moliner, P. (2014). A identidade em psicologia social. Dos processos identitários às representações sociais (2a ed.). Petrópolis, Brasil: Vozes.

Elias, N., \& Scotson, J. L. (2002). Os estabelecidos e os outsiders. Rio de Janeiro, Brasil: Zahar.

Goffman, E. (1988). Estigma: notas sobre a manipulação da identidade deteriorada (4a ed.). Rio de Janeiro, Brasil: Guanabara.

Hall, S. (2011). A identidade cultural na pósmodernidade (11a ed.). Rio de Janeiro, Brasil: DP\&A.

Human Right Watch. (2010). Herederos de los paramilitares: la nueva cara de la violencia en Colombia. Recuperado de http://www.hrw.org/es/report/2010/02/0 3/herederos-de-los-paramilitares/la-nuevacara-de-la-violencia-en-colombia

Marandola Jr., E., \& Gallo, P. M. (2010). Ser migrante: implicações territoriais e existenciais da migração. Revista Brasileira de Estudos de População, 27(2). https://doi.o $\mathrm{rg} / 10.1590 / \mathrm{S} 0102-30982010000200010$

Markoni, M. A., \& Lakatos, E. M. (2008). Técnicas de pesquisa: planejamento e execução de pesquisas, amostragens técnicas de pesquisa, elaboração, análise e interpretação de dados (7a ed.). São Paulo, Brasil: Atlas.

Moreira, J. B. (2005). A problemática dos refugiados na América Latina e no Brasil. Cadernos PROLAM/USP, 4(7), 57-76. https://doi.org/10.11606/issn.16766288.prolam.2005.81791

Oliveira, M. M. (2008). Refugiados e desplazados na Amazônia: contribuições para a sociologia 
dos deslocamentos compulsórios (Tesis de maestría sin publicar). Universidade Federal do Amazonas, Manaus, Brasil.

Oliveira, M. M. (2010). Refugiados colombianos na Amazônia: elementos para uma sociologia dos deslocamentos compulsórios. En M. M. Oliveira (Org.), Migrantes em conterxtos urbanos: uma abordagem interdisciplinar (pp. 205-222). Manaus, Brasil: FAPEAM.

Perez-Nebra, A. R., \& Jesus, J. G. (2011). Preconceito, estereótipo e discriminação. En C. V. Torres, \& E. R. Neiva (Orgs.), Psicologia social: principais temas e vertentes (pp. 219-237). Porto Alegre, Brasil: Artmed.

Phinney, J. S. (2004). Formação da identidade de grupo e mudanças entre migrantes. En S. D. Debiaggi, \& G. J. Paiva (Orgs.), Psicologia, E/Imigração e cultura (pp. 47-62). São Paulo, Brasil: Casa do psicólogo.

Silva, S. A. (2010). Hermanos amazônicos: processos identitários e estratégias de mobilidade entre peruanos e colombianos em Manaus. En S. A. Silva (Org.), Migrantes em contextos urbanos: uma abordagem interdisciplinar (pp. 205-221). Manaus, Brasil: FAPEAM.

Silva, T. T. (2014). A produção social da identidade e da diferença. En T. T. Silva (Org.), Identidade e diferença: a perspectiva dos estudos culturais (14a ed., pp. 73-102). Petrópolis, Brasil: Vozes.

Soares, C. O. (2012). O direito internacional dos refugiados e o ordenamento jurídico brasileiro: análise da efetividade da proteção nacional (Tesis de maestría sin publicar). Universidade Federal de Alagoas, Maceió, Brasil.

Souza, J. C. P., Lima, M., \& Oliveira, S. B. (2012). O sofrimento psíquico de refugiados no amazonas: dialogando com o indizivel. Recuperado de http://www.ppi.uem.br/eve ntos/artigos/38.pdf

Woodward, K. (2014). Identidade e diferença: uma introdução teórica e conceitual. En T. T. Silva (Org.), Identidade e diferença: a perspectiva dos estudos culturais (14a ed., pp. 7-72). Petrópolis, Brasil: Vozes.

\section{Notas}

* Artículo de investigación. 